\title{
Evaluation of Modulus of Elasticity by Non- Destructive Method of Hybrid Fiber Reinforced Concrete
}

\author{
Msc. Erjola Reufi, aand Prof Dr .Ing Thomas Beer
}

\begin{abstract}
Plain, unreinforced concrete is a brittle material, with a low tensile strength, limited ductility and little resistance to cracking. In order to improve the inherent tensile strength of concrete there is a need of multidirectional and closely spaced reinforcement, which can be provided in the form of randomly distributed fibers Fiber reinforced concrete (FRC) is a composite material consisting of cement, sand, coarse aggregate, water and fibers. In this composite material, short discrete fibers are randomly distributed throughout the concrete mass. The behavioral efficiency of this composite material is far superior to that of plain concrete and many other construction materials of equal cost.

The present experimental study considers the effect of steel fibers and polypropylene fiber on the modulus of elasticity of concrete. Hook end steel fibers of length $5 \mathrm{~cm}$ and $3 \mathrm{~cm}$ at volume fraction of $0.25 \%, 0.5 \%$ and $1 \%$ were used. Also polypropylene fiber of length $12,6,3 \mathrm{~mm}$ at volume fraction $0.1,0.25$ and $0.4 \%$ were used. Fifteen mixtures has been prepared to evaluate the effect of fiber on modulus of elasticity of concrete. Ultrasonic pulse velocity (UPV) and resonant frequency methods which are two non-destructive testing techniques have been used to measure the elastic properties of fiber reinforced concrete

This study found that ultrasonic wave propagation is the most reliable, easy and cost effective testing technique to use in the determination of the elastic properties of the FRC mix used in this study
\end{abstract}

Keyword-fiber reinforced concrete(FRC), polypropylene fiber, resonance, ultrasonic pulse velocity, steel fiber.

\section{INTRODUCTION}

Non destructive testing (NDT) is defined as the course of inspecting, testing on evaluating materials components without destroying the serviceability of the part or system.

(Workman \&O. Moore, 2012) [1]

Non destructive methods like rebound hammer test and ultrasound test do not damage buildings and allow to have an inventory of structure and conditions.

Non destructive test are widely applied to study mechanical properties and integrity of concrete and structures (IAEC 2005) [2].

They are simple to use and often economically advantageous. These non destructive methods are usually associated with each other to improve diagnosis and reduce the number of test.(Breysse 2012) [3].

Advantages of using NDT methods are some like vertical and lateral resolution, contrast in physical properties, signal to noise ratio, existing information about the structure [4]

Msc. Erjola Reufi, University of Tirana, Faculty of Natural Science, Department of Industrial Chemistry, Albania
The steps to choosing an adequate NDT methods are : understanding the physical nature of the material property , understanding the underlying physical processes that govern the NDT methods, understanding the physical nature of the interaction of probing field with the test material and considering economic, environmental, regulatory and other factors.[5]

Young's modulus (E) is a measure of the ability of a material to withstand changes in length when under lengthwise tension or compression.

Sometimes referred to as the modulus of elasticity, Young's modulus is equal [6] .Strain is defined as the change of the length divided by the original (initial) length where :

$$
\varepsilon=\frac{\Delta L}{L o}=\frac{L-L o}{L o}
$$

$\Delta \mathrm{l}$ is change of the length [m]

L1 length after elongation [m]

L0 original (initial) length [m] [7]

Young modulus can be calculated as:

$$
\mathrm{E}=\frac{\text { Stress }}{\text { Strain }}=\frac{F / A}{\Delta l / l o}
$$

Some of the factors that influence the value of dynamic modulus of elasticity (and/or the relationship between this and the static modulus), or that may interfere in the obtaining of the resonance frequency used to calculate the are presented below:

a. Age - Han and Kim [8] found no major correlation between sample age and the relationship between the moduli, but all samples were tested up to 28 days of age;

b. Strength - The dynamic modulus increases with increasing

strength and the higher the, the smaller the difference between and this was due to the fact that the stretch elastic of stressstrain curve tends to be straighter as the fragility of the material increases [8].

In different types of concrete, the relationship between moduli is greater as higher the strength of concrete becomes higher [9].

\section{c. Proportions of the Mixture and Aggregate Properties} - The moduli of the constituent materials affect the deformability of concrete under the influence of dynamic actions. The dynamic modulus increases with a greater amount of aggregate with the same ratio of water/cement, while an increase in the amount of water in the mixture or the content of incorporated air reduces the dynamic modulus. As also 
happens with the static modulus of elasticity, the porosity affects the matrix and transition zone.[10]

d. Specimen Size - Resonant frequency is inversely proportional to sample size.

e. Curing Conditions - The change in modulus after three or four days of air drying is very small. When the concrete is kept moist, the modulus increases with age and if the concrete is exposed to drying, the modulus decreases with age. A general recommendation is to perform submerged curing and that the sample be saturated during testing to obtain satisfactory results.[10]

\section{II.METHODOLOGY}

Based on ASTM C597-09 "Standard Test Method for Pulse Velocity through Concrete" this method based on the wave generated by an electro mechanical transducer placed on the surface of the test SPECIMENS.

This test method can be applied to assess the uniformity and relative quality of the concrete in order to indicate the presence of the void and cracks.[11]

The longitudinal velocity $\mathrm{V}$ is calculated from the distance between two transducers and electronically measured transit time. [12]

$$
\mathrm{V}=\frac{\text { Length }}{\text { Time }}
$$

Researcher have developed theoretical models for the prediction of relationship between pulse velocity and mechanical properties such as modulus of elasticity , porosity and permeability.

The relationship between Young modulus and ultrasound velocity is shown by the formula as below :

$$
\mathrm{E}=\frac{V l^{2} \rho(1+v)(1-2 v)}{1-v}
$$

$$
\begin{aligned}
& \text { V } 1 \text { - longitudinal velocity } \\
& \rho \text { - density } \\
& v \text { - coefficient off Poisson }
\end{aligned}
$$

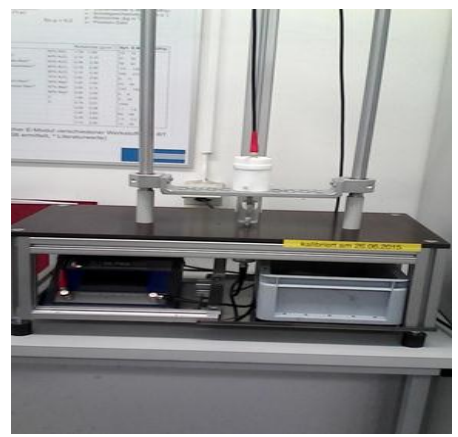

Fig 1: Determination of E Modulus by Ultrasound Method

This method is based on measuring the resonant frequency. The test arrangement can be done for flexural, longitudinal or torsional vibration. With respect to the dimensions of the specimens, the tests were done only in the longitudinal direction.[13]
Dimensions and mass of a test-piece can be easily measured. Natural frequency is determined by gently tapping the test-piece and analyzing the vibration. Tapping can be done using a small hammer or an automated tapping device.

There are different ways to detect vibrations in the testpiece: piezoelectric sensor, microphone laser vibrometer or accelerometer.

To optimize the results a microphone or a laser vibrometer can be used as there is no contact between the test-piece and the sensor. Laser vibrometer are preferred to measure signals with extreme frequencies.

These kinds of signals are usually only induced in very thin test-pieces.

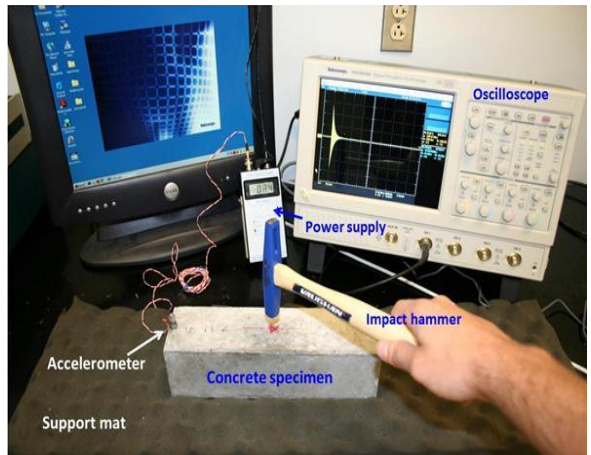

Fig 2 : Determination of E modulus by Resonance Method

Calculation of E- modulus by resonance method:

$$
\begin{gathered}
\mathrm{E}=0.9465\left(\frac{m f^{2}}{b}\right)\left(\frac{L^{3}}{t^{3}}\right) \mathrm{T} \\
\mathrm{T}=1+6.858\left(\frac{t^{2}}{L^{2}}\right)
\end{gathered}
$$

$E$ is Young's modulus

$m$ is mass

$f_{f}$ is natural frequency in flexure dimension

$b$ is width

$L$ is length

$t$ is thickness

\section{MATERIALS AND Mix PROPORTIONS}

\section{A. Materials}

The cement used in concrete mixtures was ordinary Portland cement of 32.5 grade. Fine aggregate and coarse aggregate of river of Milot with maximum size of $25 \mathrm{~mm}$ are used. Natural river sand from Milot river is used with maximum size of $5 \mathrm{~mm}$.. Two types of fibers were used for present investigation as shown in Fig. 3 Polypropylene fibers of length $12 \mathrm{~mm}, 6 \mathrm{~mm}$ and $3 \mathrm{~mm}$ and hooked end steel fiber of length $5 \mathrm{~cm}$ and $3 \mathrm{~cm}$ The properties of hooked steel fiber and polypropylene fibers are given in Tables I and II respectively. In the table $r$ is represented the mix proportion of concrete. 


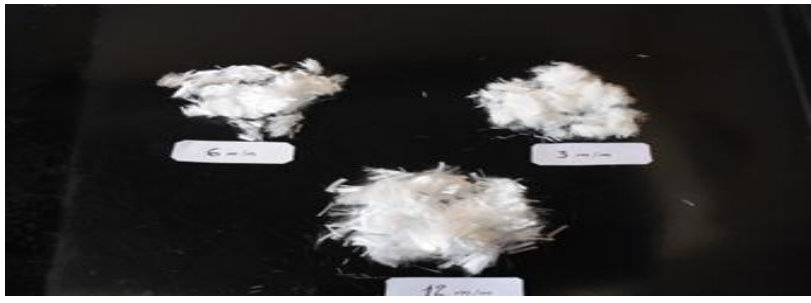

(a)

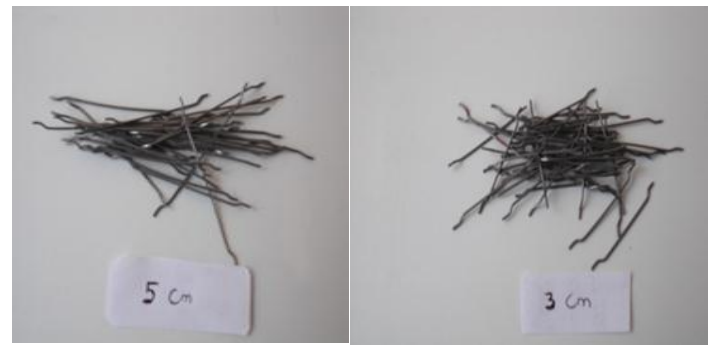

(b)

Fig. 3a Polypropylene of length $12 \mathrm{~mm}, 6 \mathrm{~mm}, 3 \mathrm{~mm}$ 3 b Steel Fiber of length $5 \mathrm{~cm}, 3 \mathrm{~cm}$

TABLE I

PROPERTIES OF STEEL FibER

\begin{tabular}{lllll}
\hline \hline Type of fiber & $\begin{array}{l}\text { Length } \\
\text { of Fiber }\end{array}$ & $\begin{array}{l}\text { Width of } \\
\text { fiber }\end{array}$ & $\begin{array}{l}\text { Aspect } \\
\text { Ratio }\end{array}$ & $\begin{array}{l}\text { Tensile } \\
\text { Strength }\end{array}$ \\
\hline $\begin{array}{l}\text { Steel Fiber } 5 \\
\text { cm SF1 }\end{array}$ & $\mathbf{5 0 ~} \mathbf{~ m m}$ & $\mathbf{0 . 7 5} \mathbf{m m}$ & $\mathbf{6 7}$ & $>\mathbf{1 1 0 0} \mathbf{M P a}$ \\
$\begin{array}{l}\text { Steel Fiber 3 } \\
\text { cm SF2 }\end{array}$ & $\mathbf{3 0 ~} \mathbf{~ m m}$ & $\mathbf{0 . 7 5} \mathbf{~ m m}$ & $\mathbf{4 4}$ & $>\mathbf{1 4 5 0} \mathbf{M P a}$ \\
\hline \hline
\end{tabular}

TABLE II

PROPERTIES OF POLYPROPYLENE FIBER

\begin{tabular}{|c|c|c|c|c|}
\hline Type of fiber & $\begin{array}{l}\text { Modulus of } \\
\text { Elasticity }\end{array}$ & Extensibility & $\begin{array}{l}\text { Melting } \\
\text { Point }\end{array}$ & $\begin{array}{c}\text { Electrical } \\
\text { Conductivity }\end{array}$ \\
\hline $\begin{array}{l}\text { Polypropylene } \\
\text { fiber } 12 \mathrm{~mm} \\
\text { P1 }\end{array}$ & $3900 \mathrm{~N} / \mathrm{mm}^{2}$ & $400 \mathrm{~N} / \mathrm{mm} 2$ & $170^{\circ} \mathrm{C}$ & Zero \\
\hline $\begin{array}{l}\text { Polypropylene } \\
\text { fiber } 6 \mathrm{~mm} \\
\text { P2 }\end{array}$ & $3700 \mathrm{~N} / \mathrm{mm} 2$ & $370 \mathrm{~N} / \mathrm{mm}^{2}$ & $170^{\circ} \mathrm{C}$ & Zero \\
\hline $\begin{array}{l}\text { Polypropylene } \\
\text { fiber } 3 \mathrm{~mm} \\
\text { P3 }\end{array}$ & $3500 \mathrm{~N} / \mathrm{mm} 2$ & $320 \mathrm{~N} / \mathrm{mm}^{2}$ & $170^{\circ} \mathrm{C}$ & Zero \\
\hline
\end{tabular}

TABLE III

Mix PROPORTION OF CONCRETE

\begin{tabular}{|c|c|}
\hline Components & $\begin{array}{c}\text { Specific gravity } \\
\mathrm{Kg} / \mathrm{m}^{3}\end{array}$ \\
\hline Sand & 900 \\
\hline Sand & 900 \\
\hline Cement & 400 \\
\hline Coarse Aggregate $10-25 \mathrm{~m}$ & 670 \\
\hline $\begin{array}{l}\text { Coarse Aggregate } \\
5-10 \mathrm{~mm}\end{array}$ & 300 \\
\hline Water & 200 \\
\hline Super plasticizier & 1 \\
\hline Steel Fiber & $\begin{array}{c}0.25 \%, 0.5 \%, 1 \% \text { by the } \\
\text { volume of concrete }\end{array}$ \\
\hline Polypropylene Fiber & $\begin{array}{l}0.1 \% 0.2, \% 0.4 \% \text { by the } \\
\text { volume of concrete }\end{array}$ \\
\hline
\end{tabular}

The specimens were prepared by using prismatic molding of $4 \mathrm{~cm} \mathrm{X} 4 \mathrm{~cm} \mathrm{X16} \mathrm{cm} \mathrm{.}$

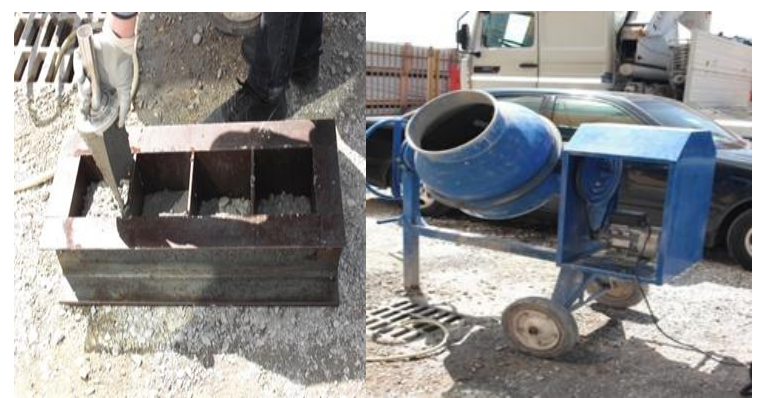

Fig 4. Mixing of samples in the mixture machine

The preparation of all test samples was prepared in a 501 concrete mixer. The mixing procedure was used is : dry mixing of aggregate in mixer $0.5 \mathrm{~min}$, dry mixing of cement and aggregate in mixer $0.5 \mathrm{~min}$ addition of water, mixing for 3 min , addition of superplasticizer and then fiber, mixing by mixer for 2.5 up to $3.5 \mathrm{~min}$ [14], [15], [16].

Ultraound Measurement

Ultrasound test were carried out at the age of 28 day, on prismatic specimens (40x40x160 mm) based on ASTM C597-09 "Standard Test Method for Pulse Velocity through Concrete" this method based on the wave generated by an electro mechanical transducer placed on the surface of the test specimens as it shown in the figure 1. E- modulus is calculated as shown in formula (2)

E- modulus measurement by resonance method

E- modulus test were carried out at the age of 28 day on prismatic specimens $(40 \mathrm{X} 40 \mathrm{X} 160 \mathrm{~mm})$ as it shown in the figure 2. E-modulus is calculated as shown in formula (3)

Results are represanted in the graphs below. In the graph number one is represanted the comparison between values of E- modulus of steel reinforced concrete measured by two methods ultrasound and resonance methods.

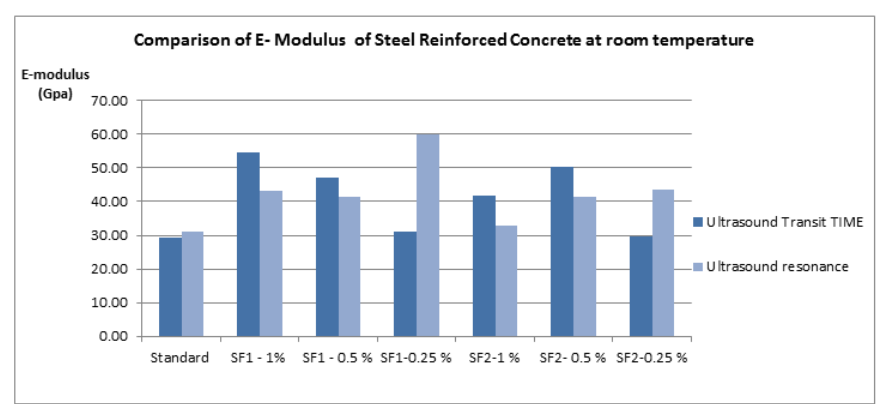

Graph 1 : Comparison of E- modulus of Steel Reinforced Concrete at room temperature

In the graph 2 is represanted the comparison between values of E- modulus of polypropylene reinforced concrete measured by two methods 


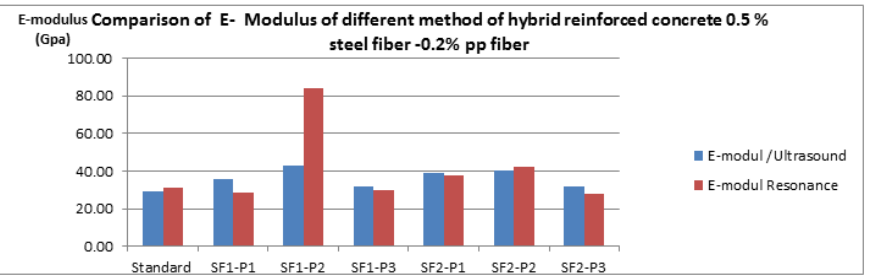

Graph 2 : Comparison of E- modulus by different method of PP fiber reinforced concrete

In th graph 3 is represanted the comparison between values of E- moduls of hybrid reinforced concrete $0.5 \%$ steel fiber in combination with $0.2 \%$ polypropylene fiber by the volume of concrete measured by two methods.

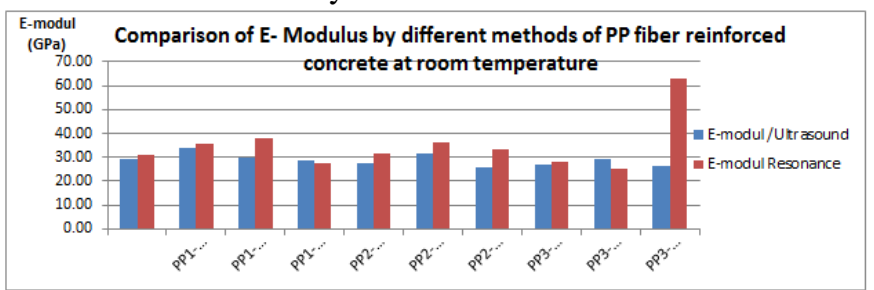

Graph 3. Comparison of E- Modulus of different method of hybrid reinforced concrete $0.5 \%$ steel fiber $-0.2 \%$ pp fiber

In the graph 4 is represanted the comparison between values of E-moduls of hybrid reinforced concrete $0.25 \%$ steel fiber in combination with $0.1 \%$ polypropylene fiber by the volume of concrete measured by two methods.

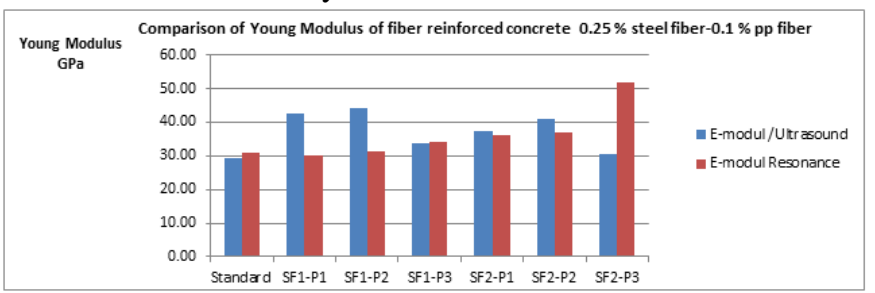

Graph 4. Comparison of Young Modulus of fiber reinforced concrete $0.25 \%$ steel fiber- $0.1 \%$ pp fiber

\section{RESULTS}

1. E modulus values measured by ultrasound method showed a increase with the increased of volume of fiber and aspect ratio for steel reinforced concrete and polypropylene reinforced concrete

2. E modulus values measured by resonance method has shown an increased with the decreased of volume of fiber and aspect ratio for steel and polypropylene reinforced concrete.

3. Among all the mixture hybrid reinforced $0.5 \%$ steel fiber- $0.2 \%$ polypropylene fiber has shown the best result.

4. In general value obtained of Young Modulus by resonance method were higher than valued of Young Modulus for all the mixture, polypropylene, steel and hybrid mixture

\section{REFERENCES}

[1] J. Helal, M. Sofi, P. Mendis Non-Destructive Testing of Concrete: A Review of Methods Special Issue: Electronic Journal of Structural Engineering 14(1) 2015

[2] J Malek , M Kaouther Destructive and Non-destructive Testing of Concrete Structures Jordan Journal of Civil Engineering, Volume 8, No. 4,2014
[3] Breysse, D. (2012). "Non-destructive evaluation of concrete strength: a historical review and a new perspective by combining NDT methods". Construction and Building Materials, 33, 139-163 http://dx.doi.org/10.1016/j.conbuildmat.2011.12.103

[4] S. Kumar Verma, S. Bhadauria, S Akhtar Review of Nondestructive Testing Methods for Condition Monitoring of Concrete Structures Journal of Construction Engineering Volume 2013 (2013)

[5] Chapter 1 Introduction to NDE Peter J. Shull The Pennsylvania State University, Altoona, Pennsylvania

[6] Encyclopedia Britannica

[7] Chapter 1 Tension and Compression in Bar D. Gross et al., Engineering Mechanics 2

[8] H. J. F. DIÓGENES, L. C. COSSOLINO Determination of modulus of elasticity of concrete from the acoustic response Volume 4, Number 5 (December, 2011) p. 792-813 • ISSN 1983-4195

[9] T. Noguchi K. M. Nemati Relationship between compressive strength and modulus of elasticity of High-Strength Concrete

[10] MALHOTRA, V.M. (1986). Testing Hardened Concrete: Nondestructive Methods. ACI Monographn ${ }^{\circ}$ 9. The Iowa State University Press.

[11] ASTM C597-09 "Standard Test Method for Pulse Velocity through Concrete"

[12] Ryan P. Carmichael Relationships between youngs modulus, compressive strength, poisson ratio and time for early age concrete.

[13] J. Kaiserlik Nondestructive testing methods to predict effect of degradation on wood a critical assessment.

[14] Beddar M , Belgara. L : Optimizing of steel fiber reinforced concrete mix desing (2013), Departament of Civil Engineering M.Sila University Algeria.

[15] ACI Committee 544, Guide for Specifying Proportioning, Mixing Placing and Finishing Steel Reinforced Concrete, ACI 544, 3R American Concrete Institute.

[16] ASTM; West Conshohocken, Pa, 1991 A.Balogh : Synthetic Fibers Concrete Construction, July 1992 pp 525-530 